\title{
UMA CIDADE, DUAS ESCOLAS: UM OLHAR PARA AS DESIGUALDADES SOCIAIS EM TEMPOS DE PANDEMIA DA COVID-19
}

\author{
Sidney Lopes Sanchez Júnior ${ }^{1}$ \\ Karina Jácob Monteiro ${ }^{2}$ \\ Silvia Gusmão Brandilla Calazans ${ }^{3}$
}

\section{RESUMO}

Este estudo tem como objetivo problematizar a questão da educação escolar remota emergencial em tempos da pandemia da Covid-19, ao eleger como foco de estudo duas escolas situadas em uma cidade do interior de São Paulo, sendo uma localizada na região central (EC) e outra em um bairro periférico (EB). Assim, assume uma abordagem qualitativa, ao analisar de forma descritiva e comparativa os dados coletados por meio de um questionário online que foi respondido por 23 professores que atuam na rede municipal de ensino. Os dados revelam fatores que podem influenciar de forma negativa e positiva no desenvolvimento das atividades remotas, dentre os quais destacam-se a falta de organização da rotina escola, a baixa renda familiar, a formação acadêmica dos pais e a falta de acesso à internet e a equipamentos tecnológicos, o que aprofunda ainda mais o abismo das diferenças e desigualdades sociais e educacionais.

Palavras-chave: Desigualdades Sociais. Pandemia da COVID-19. Educação Remota Emergencial.

\footnotetext{
1'Doutorando em Educação pela Universidade Estadual de Londrina (UEL). Mestre em Ensino pela Universidade Estadual do Norte do Paraná (UENP). ORCID: 0000-0001-5908-1982. E-mail: sid.educacaocp@gmail.com

${ }^{2}$ Mestranda em Educação pela Universidade Estadual de Londrina (UEL). Professora da Rede Pública Municipal de Ourinhos. Supervisora Técnica Pedagógica da Rede Municipal de Educação de Ourinhos-SP. ORCID: 0000-0002-4241-3335. E-mail: karinajmonteiro@gmail.com

${ }^{3}$ Mestranda em Educação e licenciada em Letras Espanhol pela Universidade Estadual de Londrina (UEL). Graduanda em Pedagogia pela Universidade Cruzeiro do Sul. ORCID: 0000-0001-5855-6421. E-mail: silgbc@gmail.com
} 


\section{ONE CITY, TWO SCHOOLS: A LOOK AT SOCIAL INEQUALITIES IN TIMES OF COVID-19 PANDEMIC}

\section{ABSTRACT}

This study aims to problematize the issue of Emergencial Remote School Education in times of the Covid-19 pandemic, by choosing as the focus of study two schools located in the countryside of São Paulo state, one school is located in the central region of the city (EC) and the other one is located in a peripheral region (EB). Thus, it takes a qualitative approach, when analyzing, in a descriptive and comparative method, the data collected through an online questionnaire that was answered by 23 teachers who work in the municipal school system. The data reveal factors that can negatively and positively influence the lack of development of remote activities, among which the organization of the school routine stands out, and also the low family income, the academic education of parents, and the difficult access to the internet and technological equipment, data that further deepen the abyss of social and educational differences and inequalities.

Keywords: Social Inequalities. COVID-19 Pandemic. Emergency Remote Education.

\section{UNA CIUDAD, DOS ESCUELAS: UNA MIRADA A LAS DESIGUALDADES SOCIALES EN TIEMPOS DE PANDEMIA DE COVID-19}

\section{RESUMEN}

Este estudio tiene como objetivo problematizar el tema de la educación escolar remota emergencial en tiempos de la pandemia de Covid-19, eligiendo como foco de estudio dos escuelas ubicadas en una ciudad en el interior de São Paulo, una ubicada en la región central (CE) y otra en un barrio periférico (EB). Por lo tanto, adopta un enfoque cualitativo al analizar de manera descriptiva y comparativa los datos recopilados a través de un cuestionario en línea que fue 
respondido por 23 maestros que trabajan en el sistema escolar municipal. Los datos revelan factores que pueden influir de manera negativa y positiva en el desarrollo de actividades remotas, entre los cuales la falta de organización de la rutina escolar, los bajos ingresos familiares, la educación académica de los padres y la falta de acceso a Internet y equipamiento tecnológico, que profundiza aún más el abismo de las diferencias y desigualdades sociales y educativas.

Palabras clave: Desigualdades Sociales. Pandemia de COVID-19. Educación Remota Emergencial.

\section{INTRODUÇÃO}

O Brasil é marcado por grandes desigualdades sociais, seja na distribuição dos recursos econômicos e culturais, como na possibilidade de ascensão social. Almeida (2017) afirma que a injustiça e a exclusão de grande parte da população quanto a bens econômicos e sociais são herança histórica, o que se confirma nos dados do Censo Demográfico brasileiro de 2010, que mesmo apresentando melhoras nos últimos dez anos, ainda são incipientes ao eliminar a pobreza ou a alta desigualdade social (IBGE, 2010).

A luta contra a pobreza é uma temática de nível mundial que, embora discutida amplamente, coloca foco na educação de maneira evidente como via para sua superação, porém autores como Bonal e Rambla (2007) e outros apontam para uma relação inversa, uma vez que as condições socioeconômicas e culturais exercem impactos nas possibilidades educacionais.

A preocupação com o desempenho e a aprendizagem de estudantes em idade de escolarização não é recente e tem suscitado pesquisas com diferentes abordagens, que buscam identificar fatores que implicam de forma negativa e positiva nessas relações. Lahire (1997) afirma que os comportamentos, ações e reações da criança não podem ser compreendidos fora de suas relações sociais, especialmente ao entender que as condições de existência perpassam antes de tudo pelas suas condições de coexistência; para o autor a criança não reproduz de forma direta o agir de suas famílias, mas se apoiam nas relações que estabelecem com todo meio social. 
Os fatores sociais internos e externos à realidade escolar podem exercer influências no desempenho e aprendizagem do indivíduo. Coleman et al. (1996), ao se preocuparem com a função da escola em promover a aprendizagem, não desprezam a forte influência do nível socioeconômico das famílias, e López (2005) destaca que as condições socioeconômicas, culturais e de subsistência das crianças que frequentam a escola são essenciais para que o projeto escolar tenha êxito.

As diferenças socioeconômicas e culturais podem auxiliar na compreensão das diferenças no desempenho escolar, uma vez que podem resultar em desigualdades educacionais. Não considerar tais fatores pode implicar em juízo de valores de uma escola em detrimento de outra (BOURDIEU, 1998). Estudos como de César e Soares (2001), Soares (2004), Soares e Andrade (2006) e Dalben (2014) explicam que não se pode analisar a escola de forma isolada de seu contexto social, tendo em vista que possui com os diferentes grupos socioeconômicos e culturais que a compõem.

Considerando tais aspectos, o objetivo deste estudo consiste em problematizar a questão da educação escolar remota em tempos da pandemia da Covid-19, ao eleger como foco de estudo duas escolas situadas em uma cidade do interior de São Paulo, sendo uma situada na região central da cidade (EC) e outra localizada em um bairro (EB).

Propõe discutir as evidências postas por estudos que realçam a desigualdade escolar juntamente com os dados empíricos coletados, sem a intenção de esgotar tal discussão, visto que esta temática envolve diferentes abordagens dos mais diversos campos do conhecimento.

Cabe destacar que a elaboração desta pesquisa se deu no contexto de uma disciplina do Programa de Pós-Graduação em Educação em uma Universidade Pública, ao instigar a discussão acerca dos fatores que implicam nas desigualdades sociais que recaem diretamente na instituição escolar.

Este trabalho se estrutura em quatro seções, compreendendo a seção intitulada "Pandemia, incertezas e exclusão", que apresenta um panorama da situação atual educacional, bem como reflete sobre as incertezas e cenário de exclusão. 
Em um segundo momento, são descritos os encaminhamentos metodológicos da pesquisa, que compreendem o movimento de todo processo de construção, elaboração e produção. Posteriormente, são apresentados os resultados e discussões; seguidos das considerações finais.

\section{PANDEMIA, INCERTEZAS E EXCLUSÃO}

Em dezembro de 2019, na cidade de Wuhan na China, foi notificado o primeiro caso de COVID-19 pelo novo coronavírus (SARS-CoV-2), o que culminou em um surto viral neste ano. Praticamente nas vésperas de uma nova década, o mundo é surpreendido com uma pandemia que se alastrou rapidamente a todos os continentes. Diante da vulnerabilidade da raça humana, a Organização Mundial de Saúde (OMS) orienta medidas de prevenção, que culminaram em isolamento social e realização de testes em massa, a fim de conter os avanços da doença e diminuir os danos à vida humana.

Enquanto se escreve esse estudo, no Brasil registram-se 74.445 mortes por COVID-19 e 1.939 .167 pessoas infectadas desde o dia 17 de março de 2020, segundo os dados do G1. O que assistimos nos noticiários são leitos de hospitais lotados e incontáveis formas em que o caos social se manifesta.

Um fenômeno sanitário sem precedentes exige tomadas de decisões e ações humanas carregadas de intenções políticas, que expõem ainda mais o modo de produção capitalista e genocida. Para Zaidan e Galvão (2020), o sistema escolhe quem merece morrer e ser desamparado quanto mais fragilizada a vida, para a eliminação dos mais fracos.

Para Santos (2020), a pandemia intensificou uma situação de crise em que a população mundial se encontrava, evidenciando as desigualdades sociais existentes e as fragilidades quanto à prestação de serviços e a um possível estado de segurança.

Apesar de promover uma consciência de comunhão coletiva, este momento possui alvos definidos, especialmente no que se refere às comunidades carentes e de maior vulnerabilidade. Mesmo atingindo a esfera global, esta situação pandêmica se torna mais 
difícil para alguns grupos sociais do que a outros (BRANDALIS; ROVANI, 2020).

Tal situação tem acarretado inquietações, medos e incertezas. Pich (2011) afirma que "certeza" é parte de uma expressão metafórica, a qual predispõe a essência do ato de pesquisar e averiguar. Para o autor:

As certezas de uma dada prática não podem ser justificadas dentro da mesma prática, visto que a sua "verdade" ali é tida por garantida, suposta a natureza mesma de um jogo de linguagem. Se certezas são postas em dúvida num jogo-delinguagem, o jogo-de-linguagem é em realidade outro, e as certezas são na realidade, ali, meras "pretensões de conhecimento" (PICH, 2011, p.182).

Mudanças impelem questionamentos, análises e movimentos de pesquisas para construção de novos saberes, sobretudo no que diz respeito a educação escolar, visto que neste período muitas mudanças aconteceram no cotidiano de professores, estudantes e famílias brasileiras. Desta maneira, a Lei Federal $n^{\circ} 13.979$, publicada no dia 6 de fevereiro de 2020 (BRASIL, 2020a), dispõe sobre as medidas para enfrentamento da emergência de saúde pública de importância internacional decorrente da pandemia do coronavírus.

Em 17 de março de 2020, pela Portaria n 343, o Ministério da Educação (MEC) propôs a substituição das aulas presenciais por aulas em meios digitais nas instituições de Ensino Superior, durante o período pandêmico (BRASIL, 2020b).

Em 18 de março de 2020, o Conselho Nacional de Educação (CNE) comunicou que todos os sistemas e as redes de ensino, de todos os níveis, etapas e modalidades, deveriam reorganizar suas atividades acadêmicas mediante as ações preventivas para a não propagação da Covid-19 (BRASIL, 2020c).

Diante dessa situação especial no cenário brasileiro, a medida provisória $n^{\circ} 934$ de $1^{\circ}$ de abril de 2020 estabelece normas excepcionais acerca do ano letivo vigente para educação básica e superior, a fim de adoção de medidas para enfrentamento da situação de emergência de saúde pública, de que trata a Lei n 13.979, 
regulamentada e operacionalizada pela portaria $n^{\circ} 356$ de 11 de março de 2020.

$\mathrm{Na}$ sequência, Conselhos Estaduais de vários estados e Conselhos Municipais de Educação emitiram resoluções e/ou pareceres a fim de orientar as instituições e os sistemas de ensino sobre a reorganização do calendário e a utilização de recursos e de atividades não presenciais.

$\mathrm{Na}$ cidade locus da pesquisa, as aulas presenciais foram suspensas por um Decreto municipal no dia 17 de março de 2020, que se estende por tempo indeterminado, em consonância com as orientações da Secretaria Estadual de Educação de São Paulo. Desde então, se vê crianças, adolescente e profissionais da educação forçados a desenvolverem suas atividades de ensino e aprendizagem em ambientes virtuais, de forma remota, o que exige equipamentos condizentes, acesso à internet para aparelhos como smartphones, computadores, notebook a fim de que assistam e participem das atividades acadêmicas mesmo que de forma precária.

É evidente que a educação emergencial remota escancarou ainda mais as desigualdades sociais e educacionais, especialmente das classes sociais menos favorecidas (pobres), negligenciando o direito subjetivo à Educação apregoado no artigo 205 da Constituição Federal (BRASIL, 1988). O momento de pandemia torna a discussão acerca da desigualdade ainda mais latente quando trazemos a tônica da exclusão das classes mais pobres. Para Martins (1997), a exclusão na verdade é um conjunto de contradições políticas e econômicas que causam vítimas, conflitos, mal-estar, inconformismo e revolta, segregação esta que cai sobre o destino dos pobres como uma condenação irremediável.

No Brasil, as políticas nem sempre favorecem a população que necessita de um olhar mais inclusivo pela falta ou precariedade das condições de vida, o que reflete em desigualdade escolar, quando não se oportuniza aos estudantes as mesmas garantias de acesso, negando um direito fundamental à uma educação de qualidade (OLIVEIRA, 2020).

Tais discussões subsidiaram a coleta e análise dos dados coletados a fim de compreender a situação de duas escolas municipais frente aos desafios encontrados pela necessidade de 
adaptação das práticas educativas, dando lugar ao ensino remoto emergencial.

\section{ENCAMINHAMENTOS METODOLÓGICOS}

É ampla a discussão sobre o modo com que as escolas têm enfrentado as dificuldades e incertezas em época de Pandemia, de maneira que muitos aspectos poderiam ser explorados e analisados neste estudo, posto as novas demandas educacionais que se descortinam. No entanto, para desemaranhar uma pequena camada que compõe a atual situação na Educação, realizou-se pesquisa de abordagem qualitativa, de cunho descritivo comparativo, com a finalidade de verificar e contrastar duas realidades escolares em relação às dificuldades atuais dos alunos em seu contexto social.

Inicialmente fez-se uso do instrumento da pesquisa bibliográfica, a fim de subsidiar as discussões acerca das desigualdades e exclusão, tendo como base autores que pesquisam a temática, como por exemplo Coleman e outros, (1996); López (2005); Cesar e Soares (2001); Soares (2004); Soares e Andrade (2006); Dalben (2014); Martins (1997); Zaidan e Galvão (2000); Oliveira (2000).

Como segundo movimento, elaborou-se um questionário em formulário online que engloba os desafios para que a educação remota emergencial aconteça, desta maneira, buscou identificar fatores que contribuem de forma positiva e/ou negativa para as práticas de ensino via plataforma digital, como: a falta de envolvimento familiar; falta de acesso à internet; organização da rotina de estudos; falta de interesse da criança; formação acadêmica dos pais; baixa renda familiar; pais que permaneceram trabalhando no período da pandemia; falta de equipamentos tecnológicos, além da identificação quanto à idade, formação, tempo de atuação na Educação Básica.

Diante da impossibilidade de fazer o levantamento por meios físicos, o instrumento foi disponibilizado de forma eletrônica, pela plataforma Formulários Google. Desta maneira, por convite, o questionário foi disponibilizado aos professores que atuam nos anos iniciais do Ensino Fundamental de duas escolas situadas em uma cidade do interior de São Paulo, uma situada na região central da 
cidade (EC) e outra localizada em um bairro periférico (EB). O questionário foi respondido por 23 professores que autorizaram em termo de consentimento livre e esclarecido a publicação de suas respostas. A fim de preservar a identidade dos participantes, quando citados no corpo do texto, foram codificados em Professor 1 (P1), Professor 2 (P2), e assim sucessivamente, de acordo com a escola a qual pertencem, ou seja, Escola Central (EC) e Escola de Bairro periférico $(E B)$.

A coleta de dados se deu na primeira quinzena do mês de julho do ano de 2020, e após este período, o acesso ao documento foi encerrado aos participantes e passou a ser restrito aos pesquisadores.

Em seguida, o material foi analisado de maneira a possibilitar a verificação das porcentagens obtidas em cada questionamento, bem como a comparação entre os achados de cada escola. Por fim, são tecidos algumas considerações acerca da pesquisa, bem como retorno ao referencial teórico para subsidiar a intepretação do material coletado.

\section{RESULTADOS E DISCUSSÕES}

A estatísticas e produção de dados muitas vezes acontecem de forma muito abstrata, ou seja, abstraídas de seus contextos, o que torna a discussão muitas vezes distante. Deste modo, serão apresentadas as características peculiares de casa instituição escolar que compõem a pesquisa, ou seja, uma Escola Central (EC) e uma Escola de Bairro (EB).

Os respectivos Projetos Político-Pedagógicos (PPP) foram disponibilizados para compor a análise desta pesquisa, cujas informações nos permitiram compreender o perfil das comunidades escolares envolvidas.

Apesar da distância entre as localidades, ambas as instituições de ensino se encontram em local servido de infraestrutura básica, com transporte público, iluminação, coleta seletiva e atendimento por Posto de Saúde. Estatisticamente, a maioria das famílias da EC recebe, em média, 2 (dois) salários mínimos, enquanto a média informada pela EB é de 1 (um) a 2 (dois) salários mínimos por 
família. Não obstante, é sabido que as famílias da EC e da EB possuem, em sua maioria, condições materiais fundamentais (geladeira, fogão, chuveiro etc.).

Com relação ao grau de escolaridade, o PPP da instituição central indica que o grau predominante entre os responsáveis pelos estudantes é o Ensino Médio, o que não ocorre na comunidade da escola de bairro, a qual está formada por familiares de escolaridade "muito baixa" (sic), muitos deles sem o Ensino Fundamental.

Quanto ao contexto familiar, os dados apontam para situações de desemprego, intervenção do conselho tutelar e separação dos pais, tanto na EC quanto na EB. No entanto, para esta última ainda há casos reportados de desnutrição, abandono, alcoolismo e prisão em algumas famílias.

Em relação à situação escolar majoritária, os alunos da EC têm horário para as tarefas escolares e estudos e contam com acompanhamento e orientação dos responsáveis para sua realização. Situação contrária ocorre com os alunos da EB, cuja minoria demonstra ter acompanhamento nos estudos e uma rotina estabelecida para tanto.

Tais perfis das comunidades das EC e EB podem ser visualizados no quadro 1 a seguir:

Quadro 1 - Perfil da comunidade escolar (EC e EB).

\begin{tabular}{|c|c|c|}
\hline $\begin{array}{c}\text { INFRA-ESTRUTURA } \\
\text { LOCAL }\end{array}$ & $\begin{array}{c}\text { Bairro Central. Servido } \\
\text { de transporte público, } \\
\text { iluminação, coleta } \\
\text { seletiva e atendimento } \\
\text { por Posto de Saúde. }\end{array}$ & $\begin{array}{c}\text { Escola do Bairro (EB) } \\
\text { central. Servido de } \\
\text { transporte público, } \\
\text { iluminação, coleta seletiva } \\
\text { e atendimento por Posto } \\
\text { de Saúde. }\end{array}$ \\
\hline SITUAÇÃO FAMILIAR & $\begin{array}{c}\text { Verificados casos de } \\
\text { desemprego, } \\
\text { intervenção do } \\
\text { conselho tutelar e } \\
\text { separação dos pais. }\end{array}$ & $\begin{array}{c}\text { Preocupa a desestrutura } \\
\text { familiar. Maioria dos pais } \\
\text { está empregada. } \\
\text { Verificados casos de } \\
\text { desemprego, desnutrição, } \\
\text { abandono, intervenção do } \\
\text { conselho tutelar, }\end{array}$ \\
\hline
\end{tabular}




\begin{tabular}{|c|c|c|}
\hline & & $\begin{array}{c}\text { alcoolismo, prisão. Mais } \\
\text { ênfase na separação dos } \\
\text { pais. }\end{array}$ \\
\hline $\begin{array}{l}\text { ESCOLARIDADE DOS } \\
\text { PAIS }\end{array}$ & $\begin{array}{c}\text { Maioria tem Ensino } \\
\text { Médio. }\end{array}$ & $\begin{array}{l}\text { Escolaridade muito baixa. } \\
\text { Ensino Fundamental } \\
\text { completo/incompleto. }\end{array}$ \\
\hline ROTINA DE ESTUDOS & $\begin{array}{l}\text { A maioria tem horário } \\
\text { para realizar as tarefas. }\end{array}$ & $\begin{array}{l}\text { Alunos demonstram não } \\
\text { ter rotina de estudos. }\end{array}$ \\
\hline $\begin{array}{l}\text { ACOMPANHAMENTO } \\
\text { FAMILIAR NOS } \\
\text { ESTUDOS }\end{array}$ & $\begin{array}{l}\text { Maioria acompanha e } \\
\text { orienta o filho na vida } \\
\text { escolar. }\end{array}$ & $\begin{array}{c}\text { Minoria acompanha e } \\
\text { orienta o filho na vida } \\
\text { escolar. }\end{array}$ \\
\hline $\begin{array}{l}\text { COMO AS CRIANÇAS } \\
\text { VÃO PARA A ESCOLA }\end{array}$ & A pé (maioria). & A pé (maioria). \\
\hline RENDA FAMILIAR & $\begin{array}{c}2 \text { salários mínimos em } \\
\text { média. }\end{array}$ & De 1 a 2 salários mínimos. \\
\hline $\begin{array}{c}\text { CONDIÇÕES } \\
\text { MATERIAIS } \\
\text { FUNDAMENTAIS }\end{array}$ & A maioria possui. & A maioria possui. \\
\hline
\end{tabular}

Fonte: Os autores (2020).

Como já explicitado, o questionário foi respondido por 23 professores que atuam nos anos iniciais do Ensino Fundamental I em uma cidade do interior de São Paulo, sendo 22 do sexo feminino e 1 do sexo masculino, com idades entre 30 a 61 anos. É importante destacar que dos dados coletados, 11 professores trabalham em uma mesma "Escola Central" (EC), enquanto os outros 12 trabalham na mesma "Escola de Bairro" (EB). Desta forma os dados apresentados serão dispostos de maneira distintas visto estabelecer uma análise comparativa destas duas realidades exploradas.

O gráfico 1 abaixo retrata $\mathrm{O}$ número de professores participantes da pesquisa e o local de trabalho (EC ou EB). 


\section{NÚMERO DE PROFESSORES PARTICIPANTES DA PESQUISA}

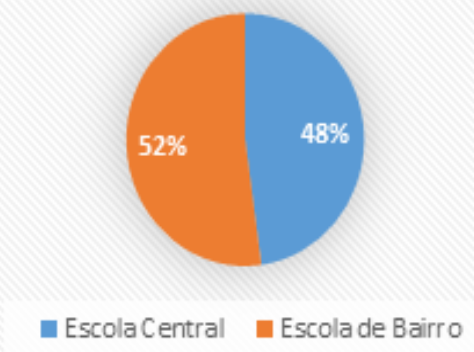

Fonte: Os autores (2020).

Acerca da formação dos professores que atuam na EC: 4 professores participantes da pesquisa relatam serem formados em curso de Licenciatura em Pedagogia, enquanto 1 afirma possuir formação em nível superior, mas não declara o curso; 3 professoras afirmam possuir pós-graduação (especialização); 1 professora participante é Mestra em Ensino de Matemática; enquanto 2 participantes não relatam sua formação.

Já os professores que atuam na EB: 3 professores relatam que possuem graduação em curso de Licenciatura em Pedagogia; 1 formada em curso de Licenciatura em Pedagogia e Direito com especialização em psicopedagogia; 3 declaram possuir formação em nível superior, contudo não indicam o curso; 1 professora é formada em Licenciatura em Pedagogia e Psicologia; 2 relatam formação em curso de pós-graduação (especialização); 1 professora com formação em Arte; e uma participante não relata sua formação. Pode-se observar que a maioria dos professores que trabalham nas duas escolas possuem formação em nível superior, em curso de Pedagogia, Especializações e apenas uma a nível de mestrado. Acerca das turmas/disciplinas e modalidade que os professores lecionam, podese observar no quadro 2 a seguir. 
Quadro 2 - Turma, modalidade, disciplina que os professores lecionam.

\begin{tabular}{|c|c|c|c|}
\hline \multicolumn{2}{|c|}{ ESCOLA CENTRAL (EC) } & \multicolumn{2}{c|}{ ESCOLA DE BAIRRO (EB) } \\
\hline $\begin{array}{c}\text { Turma/ } \\
\text { modalidade }\end{array}$ & $\begin{array}{c}\mathbf{N}^{\circ} \text { de } \\
\text { professores }\end{array}$ & $\begin{array}{c}\text { Turma/disciplina/ } \\
\text { modalidade }\end{array}$ & $\begin{array}{c}\mathbf{N}^{\circ} \text { de } \\
\text { professores }\end{array}$ \\
\hline $1^{\circ}$ ano & 3 & $1^{\circ}$ ano & 3 \\
\hline $2^{\circ}$ ano & 1 & $2^{\circ}$ ano & 2 \\
\hline $3^{\circ}$ ano & 1 & $3^{\circ}$ ano & 2 \\
\hline $4^{\circ}$ ano & 2 & $4^{\circ}$ ano & 2 \\
\hline $5^{\circ}$ ano & 1 & $5^{\circ}$ ano & 1 \\
\hline Educação Especial & 3 & Educação Especial & 1 \\
\cline { 2 - 4 } & & Arte & 1 \\
\hline
\end{tabular}

Fonte: Os autores (2020).

Os professores participantes da pesquisa indicaram o número de alunos em cada turma, bem como o número de estudantes que tem acessado as atividades remotas dispostas semanalmente na plataforma digital adotada pela rede municipal de educação. 0 quadro 3 e 4 a seguir explicitam esses números, o que torna possível estabelecer uma comparação entre as duas realidades (EC e EB) foco desta pesquisa.

Quadro 3 - Estudantes que acessam e não acessam as plataformas digitais na EC.

\begin{tabular}{|l|l|l|l|l|}
\hline $\begin{array}{l}\mathbf{N}^{\circ} \text { de alunos } \\
\text { atendidos } \\
\text { pelos } \\
\text { professores }\end{array}$ & $\begin{array}{l}\mathbf{N}^{\circ} \text { de alunos } \\
\text { que acessam } \\
\text { as plataformas } \\
\text { digitais }\end{array}$ & \% aprox. & $\begin{array}{l}\mathbf{N}^{\circ} \text { de alunos que } \\
\text { não acessam as } \\
\text { plataformas } \\
\text { digitais }\end{array}$ & \% aprox. \\
\hline
\end{tabular}


Fonte: Os autores (2020).

Observa-se que dos 193 alunos atendidos na EC pelos professores participantes da pesquisa, a maioria $(72,5 \%)$ tem acesso as atividades pela plataforma digital, visto que $27,5 \%$ não acessam, o que também é uma quantidade expressiva a ser considerada. Os dados referentes a Escola do Bairro (EB) são dispostos no quadro 4 abaixo.

Quadro 4 - Estudantes que acessam e não acessam as plataformas digitais na EB.

\begin{tabular}{|c|c|c|c|c|}
\hline $\begin{array}{c}\mathbf{N}^{\circ} \text { de } \\
\text { alunos } \\
\text { atendidos } \\
\text { pelos } \\
\text { professores }\end{array}$ & $\begin{array}{c}\mathbf{N}^{\circ} \text { de alunos } \\
\text { que acessam as } \\
\text { plataformas } \\
\text { digitais }\end{array}$ & \% aprox. & $\begin{array}{c}\mathbf{N}^{\circ} \text { de alunos } \\
\text { que não } \\
\text { acessam as } \\
\text { plataformas } \\
\text { digitais }\end{array}$ & $\%$ aprox. \\
\hline 174 & 60 & $34 \%$ & 114 & $66 \%$ \\
\hline
\end{tabular}

Fonte: Os autores (2020).

Os dados da EB revelam que a maior parte dos estudantes não acessam as atividades dispostas na plataforma digital, ou seja, aproximadamente $66 \%$ dos alunos atendidos pelos professores participantes da pesquisa. Cabe destacar que a estratégia adotada pelo município em questão não atende de forma igualitária todos os estudantes das escolas municipais, o que requer um olhar mais apurado sobre as dificuldades, estratégias que os profissionais têm adotado a fim de viabilizar o atendimento daqueles que não acessam as atividades via plataforma digital.

Cabe destacar que dentre os professores que participaram da pesquisa, a professora de Arte declarou que atende aproximadamente 300 alunos, e que poucos estudantes acessam as atividades da sua disciplina na plataforma digital, confirmando os dados apresentados acima.

Desta maneira, o gráfico 2 e 3 dispõem as percepções dos professores das escolas estudadas sobre as dificuldades encontradas 
neste momento para o desenvolvimento das atividades escolares remotas neste tempo de pandemia da Covid-19.

Gráfico 2 - Dificuldades elencadas pelos professores da EC para o desenvolvimento das atividades escolares remotas.

\section{DIFICULDADES PARA O ENSINO REMOTO EMERGENCIAL (EC)}
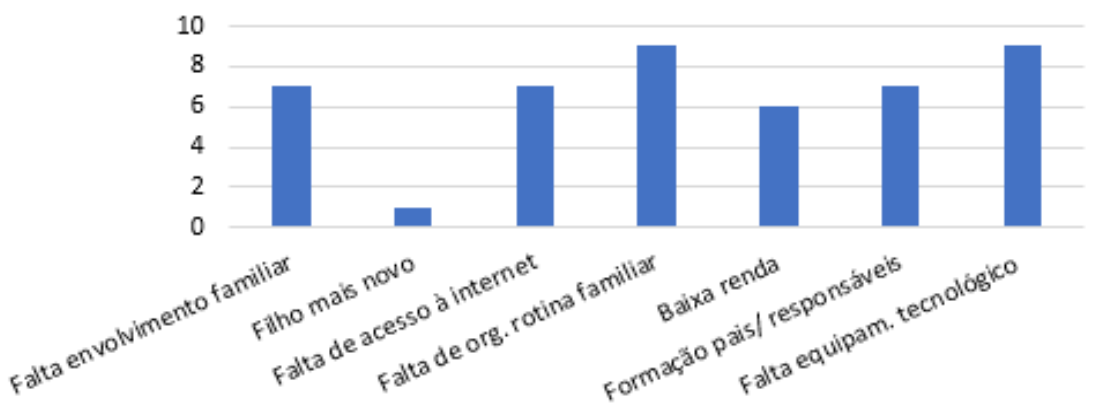

Fonte: Os autores (2020).

Os professores da EC que participaram da pesquisa, 7 apontaram para falta de envolvimento familiar; 1 pelo fato de ser filho mais novo; 7 a falta de acesso à internet; 9 destacaram a falta de organização da rotina familiar; 6 a baixa renda; 7 evidenciam a falta de formação dos pais ou responsáveis; e 9 destacaram a falta de equipamentos tecnológicos em casa. $O$ gráfico 3 a seguir retrata a percepção das professoras da EB sobre as dificuldades que encontram nas atividades educacionais remotas.

Gráfico 3 - Dificuldades elencadas pelos professores da EB para o desenvolvimento das atividades escolares remotas.

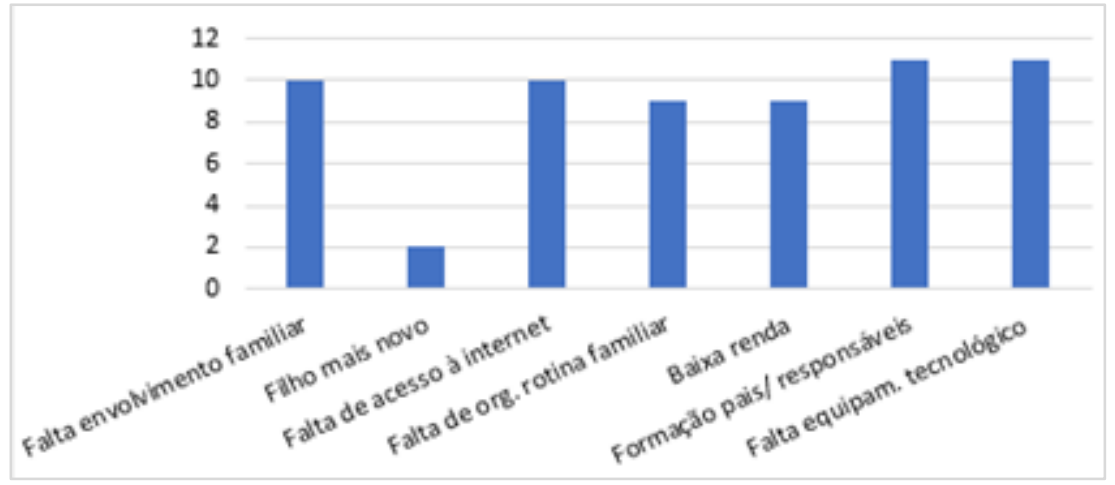


Fonte: Os autores (2020).

Das dificuldades destacadas pelos professores da EB, observam-se: 10 apontam a falta de envolvimento familiar; enquanto 2 destacam o fato da criança ser o filho (a) mais novo (a); 10 salientam a falta de acesso à internet; 9 expõem a falta de organização da rotina familiar; 9 realçam a baixa renda; e 11 indicam a dificuldade causada pela falta de formação dos pais e a falta de equipamentos tecnológicos em casa.

Ao comparar os dados das duas escolas, é possível observar que as dificuldades mais salientes da EB são a falta de envolvimento familiar, falta de acesso à internet; formação dos pais, seguidos de baixa renda e falta de organização familiar. Já a EC, as dificuldades mais aparentes se instalam na falta de equipamentos tecnológicos em casa. A renda familiar não foi o fator mais evidente nos apontamentos dos professores participantes da pesquisa, o que pode revelar que a $\mathrm{EC}$ atende um público que possui maior renda familiar em relação as crianças matriculadas na EB.

Do mesmo modo, os professores destacaram fatores que consideram importantes e que contribuem para o envolvimento e participação das crianças nas atividades escolares remotas. Os gráficos 4 e 5 a seguir expressam as percepções dos professores (EC e EB) sobre a questão.

Gráfico 4 - Fatores que contribuem para realização de atividades escolares remotas - EC

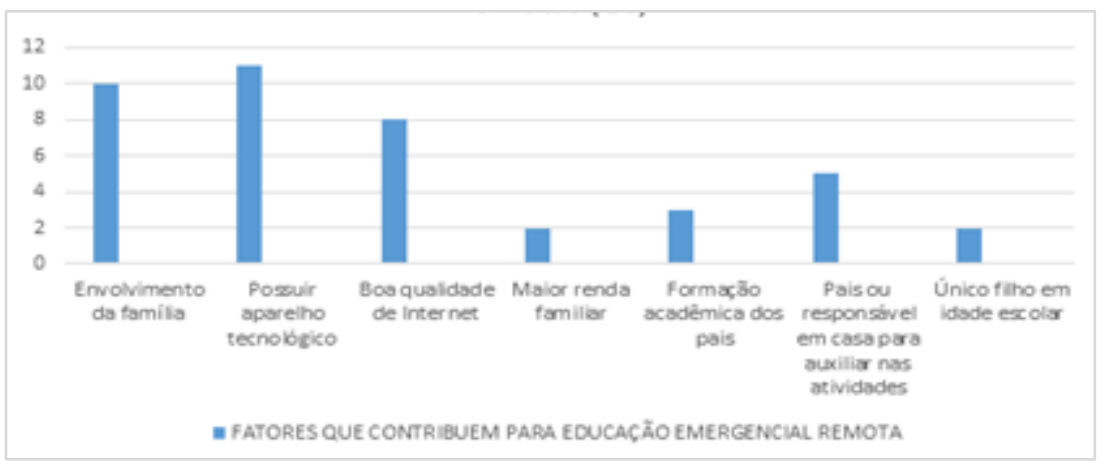

Fonte: Os autores (2020). 
Os professores da EC elencaram fatores que contribuem para o desenvolvimento das atividades remotas, sendo: 10 apontam a importância do envolvimento da família; 11 destacam o fato de possuírem aparelho tecnológico; 8 declaram a boa qualidade da internet; 2 denotam as famílias que possuem maior renda familiar; 3 destacam a importância da formação acadêmica dos pais; 5 reforçam que a presença dos pais ou responsáveis em casa para auxiliar nas atividades escolares; e 2 destacam que o fato de serem filho único contribui positivamente para desenvolver as atividades remotas. Os fatores que os professores da EB elencaram estão dispostos no gráfico 5.

Os fatores que contribuem para a realização das atividades remotas que os professores da EB destacaram, podem ser descritos: os 12 professores, ou seja, $100 \%$ destacam o papel do envolvimento familiar; 10 destacam a importância de possuírem aparelhos tecnológicos; 11 realçam a boa qualidade do acesso à internet; 8 colocam em evidência a maior renda familiar; 8 evidenciam o envolvimento dos pais na realização das atividades; e 2 realçam o fato de que a criança é o único filho em idade escolar da família.

Gráfico 5 - Fatores que contribuem para realização de atividades escolares remotas - EB

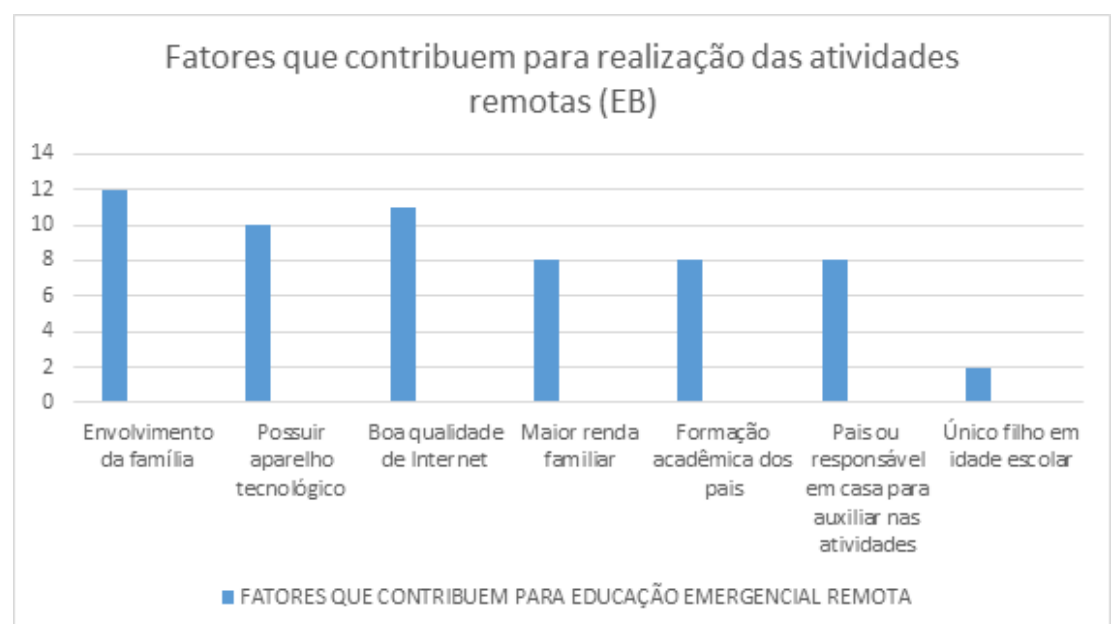

Fonte: Os autores (2020). 
Os participantes da pesquisa também foram questionados acerca das estratégias que têm utilizado para viabilizar as atividades escolares, bem como ações que minimizem os efeitos do distanciamento social por parte das crianças e o ambiente escolar. Assim, como já mencionado, 11 professores da EC aceitaram participar da pesquisa, e, a fim de garantir o sigilo da identidade destas pessoas, o quadro 5 abaixo apresenta as estratégias utilizadas pelas professoras que foram codificadas em professora 1 (P1), professora 2 (P2), professora 3 (P3), assim sucessivamente.

Quadro 5 - Estratégias e ações no período de Educação Remota Emergencial na EC.

\begin{tabular}{|l|l|}
\hline \multicolumn{1}{|c|}{ Estratégias e ações } & \multicolumn{1}{|c|}{ Professores } \\
\hline Vídeos explicativos & $\mathrm{P} 1, \mathrm{P} 2, \mathrm{P} 9$ \\
\hline Vídeos animados & $\mathrm{P} 1$ \\
\hline $\begin{array}{l}\text { Áudios com orientações em grupos de } \\
\text { WhatsApp }\end{array}$ & $\mathrm{P} 1, \mathrm{P} 2, \mathrm{P} 3, \mathrm{P} 9$ \\
\hline $\begin{array}{l}\text { Trabalho da equipe gestora (Busca } \\
\text { ativa) }\end{array}$ & $\mathrm{P} 1, \mathrm{P} 6, \mathrm{P} 8, \mathrm{P} 10$ \\
\hline $\begin{array}{l}\text { Atividades impressas para quem não } \\
\text { tem acesso à internet }\end{array}$ & $\mathrm{P} 1, \mathrm{P} 2, \mathrm{P} 5, \mathrm{P} 6, \mathrm{P} 7, \mathrm{P} 8, \mathrm{P} 9$ \\
\hline Atividades na plataforma digital & $\mathrm{P} 2, \mathrm{P} 8$ \\
\hline Sacola de atividades & $\mathrm{P} 8$ \\
\hline Contação de Histórias & $\mathrm{P} 9$ \\
\hline Atividades musicais & $\mathrm{P} 9$ \\
\hline Telefonando para os familiares & $\mathrm{P} 3, \mathrm{P} 9, \mathrm{P} 10$ \\
\hline $\begin{array}{l}\text { Indo à residência das crianças que não } \\
\text { conseguem se comunicar via internet }\end{array}$ & $\mathrm{P} 3$ \\
\hline
\end{tabular}


Reuniões virtuais com pais e professores

Fonte: Os autores (2020).

Da mesma forma, os 12 professores da EB que participaram da pesquisa responderam ao questionário indicando as estratégias e ações que têm desenvolvidos neste período de educação emergencial remota para que as crianças tenham acesso às atividades escolares. Desta maneira, os 12 professores foram codificados em Professora 1 (P1), Professora 2 (P2), professora 3 (P3), assim sucessivamente, a fim de garantir o sigilo de suas identidades, conforme quadro 6 a seguir.

Quadro 6 - Estratégias e ações no período de Educação Remota Emergencial na EB.

\begin{tabular}{|l|l|}
\hline \multicolumn{1}{|c|}{ Estratégias e ações } & \multicolumn{1}{|c|}{ Professores } \\
\hline Orientações em grupos de WhatsApp & $\mathrm{P} 4, \mathrm{P} 5, \mathrm{P} 7$ \\
\hline $\begin{array}{l}\text { Trabalho da equipe gestora (Busca } \\
\text { ativa). }\end{array}$ & $\mathrm{P} 1, \mathrm{P} 2, \mathrm{P} 3$ \\
\hline $\begin{array}{l}\text { Atividades impressas para quem não } \\
\text { tem acesso à internet }\end{array}$ & \begin{tabular}{l}
$\mathrm{P} 1, \mathrm{P} 3, \mathrm{P} 4, \mathrm{P} 5, \mathrm{P} 6, \mathrm{P} 7, \mathrm{P} 8, \mathrm{P} 9$, \\
\hline Atividades na plataforma digital
\end{tabular} \\
\hline Telefonando para os familiares & $\mathrm{P} 2, \mathrm{P} 6$ \\
\hline
\end{tabular}

Fonte: os autores (2020).

Visto que a escola tem um número menor de estudantes que acessam a plataforma digital, observa-se que a estratégia mais utilizada é a impressão de atividades para a realização em casa juntamente com as famílias ou responsáveis. 
Fica evidente que a rotina dos alunos, de suas famílias e dos profissionais mudou, bem como o ensino e aprendizagem nesta pandemia. Porém, conforme a análise dos dados, mesmo em uma mesma cidade é possível observar diferenças e desigualdades, o que evidencia que o ensino de forma remota exige maior atenção por parte dos governantes, equipe gestora, demais profissionais da educação e familiares.

\section{CONSIDERAÇÕES FINAIS}

Uma pandemia obrigou todos a adotarem medidas de isolamento social, o que exigiu mudanças na maneira de relacionar, interagir, comunicar, ensinar e aprender. Todos foram obrigados a modificar "as regras no meio do jogo", causando incertezas e insegurança, o que nos leva a pensar possibilidades e limites no contexto educacional, gerando novas aprendizagens e com experiências de como fazer e ser escola em pleno século XXI.

O contato humano tão importante para todos e principalmente para as crianças foi substituído por uma tela que até então era o refúgio de tantos, se torna o único caminho para a vivência e socialização. O que era antes uma forma de distração passa a ser uma obrigação.

Professores e gestores de todas as etapas e modalidades da educação precisaram e ainda precisam repensar, resinificar suas práticas, visto que a adoção de uma única estratégia atinge a todos, sobretudo pelo fato das diferentes configurações familiares; de acesso à internet, equipamentos tecnológicos, renda familiar, rotina de estudos, dentre tantos outros fatores que escancaram ainda mais o abismo das desigualdades sociais e educacionais.

O ambiente escolar, além de garantir um espaço de aprendizagem, assegura a possibilidade de alimentação, proteção, segurança, que para muitos que fora dela, estão expostos as mais diversas formas de violência, visto que tais mudanças exigiram que as tarefas escolas sejam realizadas nos lares, e que por falta de organização, formação acadêmica pode gerar situações conflituosas, estressantes e até mesmo traumáticas. 
Diante deste cenário caótico de crise sanitária, educacional e política, cada um é forçado a cumprir o seu papel, como se fôssemos peças de um enorme tabuleiro de um jogo, nunca antes jogado: o governo lança a medida provisória e o Conselho Nacional de Educação dita as normas a serem seguidas, e então, novas regras se estabelecem; as secretarias municipais de educação jogam os dados ao estruturarem a organização da educação remota, juntamente com toda a equipe; as escolas, por sua vez, organizam os peões, que são os diretores, os coordenadores e os professores, para que o novo processo educacional se desenvolva, iniciando do ponto de partida pré-estabelecido; e os filhos, em companhia de seus pais, aguardam as instruções na tentativa de não perder mais uma vez.

O cenário educacional brasileiro sempre foi marcado por inúmeras fragilidades que ficaram ainda mais evidentes com advento da pandemia e agudizadas pelo fato do ensino e aprendizagem acontecerem de forma remota, o que leva a inúmeros questionamentos:

Como garantir a todos o acesso à Educação de qualidade, visto que muitos não conseguem ter o acesso remoto? Diante de tantas ações políticas, será que a educação está sendo testada para se transformar em um abismo ainda maior e mais profundo entre os que detém maior poder econômico e aqueles que podem perder o direito a educação pública, universal, gratuita e de qualidade?

A educação remota emergencial ilustra a exclusão e mais uma vez a crise na educação, visto que ainda há muitos desafios para superar; desafios estes que a escola tampouco dá conta, especialmente por fazer parte de uma sociedade tão desigual.

\section{REFERÊNCIAS}

ALMEIDA, L. C. As desigualdades e o trabalho das escolas: problematizando a relação entre desempenho e localização socioespacial. Revista Brasileira de Educação, v. 22 n. 69 abr./jun. 2017.

BONAL, X.; RAMBLA, X, "In the name of globalization": southern and northern paradigms of educational development. In: DALE, R.; 
ROBERTSON, S. (Orgs.). Globalization and europeanization in education. Oxford: Symposium Books, 2007. p. 143-158

BOURDIEU, P. Escritos de educação. Petrópolis: Vozes, 1998.

BRANDALISE, C.; ROVANI, A. 100 dias que mudaram o mundo. Universa, $2020 . \quad$ Disponível em: https://www.uol.com.br/universa/reportagens-

especiais/coronavirus-100-dias-que-mudaram-o-mundo/. Acesso em: 24 jun. 2020.

BRASIL tem 74.445 mortes por coronavírus e 1.939.167 infectados. G1, 15 jul 2020. Disponível em: https://g1.globo.com/g1-em-1minuto/video/g1-em-1-minuto-brasil-tem-74445-mortes-porcoronavirus-e-1939167-infectados-8700439.ghtml. Acesso em: 15 jul. 2020.

BRASIL. Constituição (1988). Constituição da República Federativa do Brasil. Brasília, DF: Senado Federal: Centro Gráfico, 1988.

BRASIL. Lei Federal n 13.979, de 6 de fevereiro de 2020. Dispõe sobre as medidas para enfrentamento da emergência de saúde pública de importância internacional decorrente do coronavírus responsável pelo surto de 2019. Diário Oficial da União: seção 1, Brasília, DF, ano 158, n. 27, p. 1, 7 fev. 2020a.

BRASIL. Ministério da Educação. Conselho Nacional de Educação. Proposta de parecer sobre reorganização dos calendários escolares e realização de atividades pedagógicas não presenciais

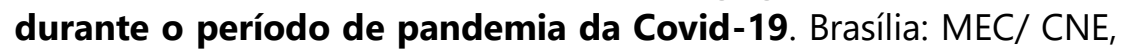
2020c. Disponível em: http://portal.mec.gov.br/index. php?option=com_docman\&view =download\&alias $=144511$-texto referencia-reorganizacao-dos-calendarios-escolares-pandemiadacovid- 19\&category_slug=marco-2020-pdf\&ltemid=30192. Acesso em: 24 jun. 2020.

BRASIL. Portaria no 343, de 17 de março de 2020. Dispõe sobre a substituição das aulas presenciais por aulas em meios digitais enquanto durar a situação de pandemia do Novo Coronavírus Covid-19. Diário Oficial da União: Seção 1, Brasília, DF, ano 158, n. 53, p. 39, 8 mar. 2020b. 
CESAR, C. C.; SOARES, J. F. Desigualdades acadêmicas induzidas pelo contexto escolar. Revista Brasileira de Estudos de População, Rio de Janeiro: ABEP, v. 18, n. 1/2, p. 97-110, jan./dez. 2001.

COLEMAN, J. S. et al. Equality of educational opportunity. Washington: Office of Education and Welfare, 1966.

DALBEN, A. Fatores associados à proficiência em leitura e matemática: uma aplicação do modelo linear hierárquico com dados longitudinais do Projeto Geres. 2014.400p. Tese (Doutorado em Educação) - Universidade Estadual de Campinas, Campinas, 2014.

IBGE - Instituto Brasileiro de Geografia e Estatística. Censo Brasileiro de 2010. Rio de Janeiro: IBGE, 2010. Disponível em: https://censo2010.ibge.gov.br/resultados.html. Acesso em: 24 jun. 2020.

LAHIRE, B. Sucesso Escolar nos meios populares. As razões do improvável. Editora Ática, 1997.

LÓPEZ, N. Educación y equidad. Algunos aportes desde la noción de educabilidad. In: Hernaiz, I.; Chávez, E. S.; Villarán, V. (Orgs.). Educación y desarrollo local: tensiones y perspectivas. Reflexiones sobre experiencias en la región andina. Buenos Aires: IIPE- -UNESCO, 2005.

MARTINS, J. S. Exclusão social e a nova desigualdade. São Paulo: Paulus, 1997.

OLIVEIRA, F. L. Educação transformada em Ead durante a pandemia: Quem é que está por trás dessa ação? In: AUGUSTO, C. B.; SANTOS, R. D. Pandemias e Pandemônio no Brasil. Instituto Defesa da classe trabalhadora. $1^{\circ}$ ed. São Paulo - SP, 2020.

PICH, R. W.. Sobre Certeza, Regras e Normas. In: CARVALHO, H.; CARVALHO, M. Temas de Ética e Epistemologia. Teresina: EDUFPI, 2011. p. 182-190.

SANTOS, B. S. A cruel pedagogia do vírus. Coimbra/PT: Almedina, 2020. 
SOARES, J. F. O efeito da escola no desempenho cognitivo de seus alunos. REICE: Revista Electrónica Iberoamericana sobre Calidad, Eficacia y Cambio en Educación, v. 2, n. 2, p. 83-104, 2004.

SOARES, J. F.; Andrade, R. J. Nível socioeconômico, qualidade e equidade das escolas de Belo Horizonte. Ensaio: Avaliação e Políticas Públicas Educacionais, Rio de Janeiro, v. 14, n. 50, p. 107126, jan./mar. 2006.

ZAIDAN, J. M.; GALVÃO, A. C. COVID-19 e os abutres do setor educacional: A superexploração da força de trabalho escancarada. In: AUGUSTO, C. B.; SANTOS, R. D. Pandemias e Pandemônio no Brasil. 1. ed. São Paulo: Instituto Defesa da classe trabalhadora, 2020.

Submetido em: Agosto/ 2020.

Aceito em: Março/ 2021. 